\title{
Ionic Conductivity of Chitosan-Lithium Electrolyte in Biodegradable Battery Cell
}

\author{
Benouar Ali ${ }^{1,2, *}$ and Ahmed Bacha Reda Mohammed ${ }^{2}$ \\ ${ }^{1}$ Laboratoire de Physico-Chimie des Matériaux, Environnement et Catalyse, Université des Sciences et de la Technologie d'Oran \\ Mohammed Boudiaf, M’Nouar BP, 1505, Oran, Algérie
}

${ }^{2}$ Ecole Supérieure en Génie Électrique et Énergétique, Oran, Algérie

\section{* Corresponding author:}

email: benouardz@yahoo.fr

Received: April 22, 2019

Accepted: September 23, 2019

DOI: $10.22146 / \mathrm{ijc} .45283$

\begin{abstract}
The electrical conductivities of salts ( $\mathrm{LiCl}, \mathrm{LiOH})$ in chitosan as an electrolyte in biodegradable batteries have been measured at the concentration range 10-100 mol $\mathrm{m}^{-3}$ in the temperature range 278-308 $\mathrm{K}$. The data were interpreted in terms of ion-ion and ion-solvent interactions using the Fuoss paired ion. The fitting of Fuoss' equation of 1978 to these data led us to an estimate of the ionic association by computing the conductimetric pairing constants. In order to optimize the use of the electrolyte in the clean lithium battery, the temperature dependency of conductivity will be studied using Arrhenius empirical equation. This equation was applied successfully in the temperature range used in this study.
\end{abstract}

Keywords: electrical conductivity; biodegradable batteries; chitosan; clean energy

\section{- INTRODUCTION}

In recent years, the development of polymer electrolytes has been a central challenge to be faced by academic and industrial interests [1-2]. These materials have vast potential applications in various electrochemical devices [3-5]. They offer many advantages under liquid electrolytes, such as no internal shorting, leakage of electrolytes and non-combustible reaction products at the electrode surface existing in the liquid electrolytes [6]. Chitosan has been under extensive research on account of its specific properties, such as being non-toxic and biodegradable and also because of its promising potential in biomedical, pharmaceutical, and industrial applications [7-8]. Chitosan also constitutes a polymer host for electrolyte as it is able to dissolve ionic salts [9].

Electrical conductivity, the most vital electrolyte properties of chitosan, can be increased by several methods. Rosli et al. [10] studied the effect of $\mathrm{TiO}_{2}$ filler on the structure and electrical properties of hexanoyl chitosan/polystyrene based electrolytes. The conductivity for filler-free polymer electrolyte is $7.21 \times 10^{-5} \mathrm{~S} \mathrm{~cm}^{-1}$. The addition of 4 wt. $\% \mathrm{TiO}_{2}$ increased the conductivity by one order of magnitude to $2.27 \times 10^{-4} \mathrm{~S} \mathrm{~cm}^{-1}$. Yulianti et al. [11] have successfully studied Ion Implantation Technique to prepare a solid-state electrolyte based on chitosan. Various ion salts ( $\mathrm{Li}, \mathrm{Cu}, \mathrm{Ag}$ ) was involved in the chitosan matrix. The results show that after implanted with $\mathrm{Li}, \mathrm{Cu}$ or $\mathrm{Ag}$ ion, the conductivity of chitosan film increased significantly. Traditional lithium salts used in polymer electrolytes are $\mathrm{LiPF}_{4}, \mathrm{LiClO}_{4}, \mathrm{LiBF}_{4}$, etc.

Up to now the lithium - ion batteries used specific electrolytes $\mathrm{LiPF}_{4}, \mathrm{LiPF}_{6}$, etc., dissolved in organic solvents such as Propylene Carbonate (PC) Acetonitrile (AN), etc. Our goal in this research is to substitute the toxic solvents (PC, AN) by the biodegradable and nontoxic solvent "Chitosan", with a view to elaborate a lithium-ion battery based on this clean and biodegradable solvent. We find it interesting to make measurements of conductivity with a lithium salt. This is performed in order to optimize the electrolyte composition to be used in a clean lithium battery without the use of toxic solvents like Propylene Carbonate (PC) and Acetonitrile (AN). The experimental conductance data will be analyzed by the known equations of the literature namely the Fuoss equation of 1978, Casteel-Amis empirical equation and Arrhenius empirical equation for the temperature dependence of the conductivity. 


\section{- EXPERIMENTAL SECTION}

Electrolytes with lithium salts, lithium chloride $(\mathrm{LiCl})$ and Lithium hydroxide $(\mathrm{LiOH})$ were prepared with distilled water and Chitosan. The $\mathrm{LiCl}$ and $\mathrm{LiOH}$ salts had a purity grade of $99.5 \%$ and $99 \%$, respectively. The initial solution concentration for each electrolyte was prepared by weight using the electronic balance Ohaus As200. For the electrolyte solution, the concentrated solution was obtained by simply adding the necessary mass of lithium salts to the previous solution. Depending on its mass, lithium salts will require a period between $1-4 \mathrm{~h}$ to be completely dissolved using a magnetic stirrer. To prepare the polymer electrolyte, $0.5 \mathrm{~g}$ of chitosan was dissolved in $50 \mathrm{~mL}$ of acetic acid at $3 \% \mathrm{vol} / \mathrm{vol}$. For the desired concentration, the lithium salt was added, and the mixture was placed in a magnetic stirrer at $313 \mathrm{~K}$ for $18 \mathrm{~h}$. All prepared solutions were covered by paraffin.

The conductivity measurements were carried out using the EC215 conductivity meter (Hanna Instruments) having a resolution of $0.01 \mu \mathrm{S} \mathrm{cm}^{-1}$, a precision of $1 \%$ and an automatic correction of temperature shift during the measurement. Before use, the instrument was calibrated using the standard $\mathrm{KCl}$ solution $\mathrm{HI} 7031$. The solution was placed into a special dual wall cell suitable for temperature control and connected to the cryostat (Lauda RE1050- CP) filled with ethylene glycol where the desired temperature was kept constant (Fig. 1).

\section{Theoretical Equations}

\section{Fuoss's model}

According to Fuoss's paired ion model, an equilibrium may be established through the following reaction [12]:

$\mathrm{A}^{+}+\mathrm{B}^{-} \leftrightarrow\left(\mathrm{A}^{+} \ldots \mathrm{B}^{-}\right) \leftrightarrow\left(\mathrm{A}^{+} \mathrm{B}^{-}\right) \leftrightarrow(\mathrm{AB})$

$\mathrm{A}^{+}$and $\mathrm{B}^{-}$are free ions; $\left(\mathrm{A}^{+} \cdots \mathrm{B}^{-}\right)$are solvent separated pairs; $\left(\mathrm{A}^{+} \mathrm{B}^{-}\right)$are contact pairs and $(\mathrm{AB})$ are neutral molecules.

In this theory, the effects of ion-ion and ion-solvent interactions enter through two adjustable parameters, the parameter $\alpha$ and Gurney radius $\left(\mathrm{R}_{\mathrm{g}}\right)$. The parameter $\mathrm{Rg}$ is the radius of the spherical portion of the solvent that encloses the ion. The parameter $(\alpha)$ is a fraction defined by

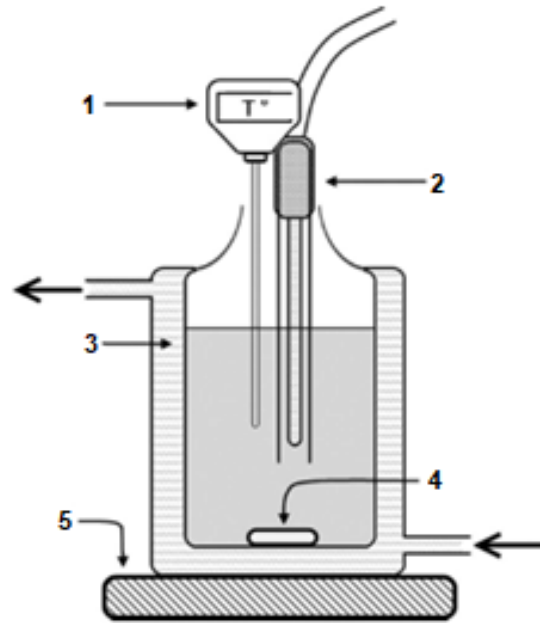

Fig 1. Experimental diagram. 1: Thermometer; 2: Electrical conductivity probe; 3: Heat-transfer fluid (Ethylene glycol); 4: Magnetic stir bars; 5: Magnetic stirrer

classifying each ion according to the magnitude of $r$, the distance from the center of the ion to that of the nearest neighbor of opposite sign. If $r>R$, then the ion is unpaired, otherwise the ion is said to be paired. If $r<<$ $R$, the paired ion and its neighbor constitute a contact pair which does not contribute to the conduction process. The experimental data were analyzed using Fuoss' conductance equation, expressed as:

$\Lambda=\mathrm{P}\left[\Lambda_{0}(1+\mathrm{RX})+\mathrm{EL}\right]$

$\mathrm{P}=1-\alpha(1-\gamma)$

$\gamma=1-\mathrm{K}_{\mathrm{A}} \mathrm{C} \gamma^{2} \mathrm{f}^{2}$

$-\ln f=\frac{\beta \kappa}{2(1+\kappa R)}$

$\beta=\frac{\mathrm{e}^{2}}{\varepsilon \mathrm{k}_{\mathrm{b}} \mathrm{T}}$

$\mathrm{K}_{\mathrm{A}}=\mathrm{K}_{\mathrm{R}}\left(1+\mathrm{K}_{\mathrm{S}}\right)$

In these equations, $\mathrm{R}$ represents the Gurney radius; $\gamma$ the fraction of unpaired ions (free ions); $p$ the fraction of solvent-separated pairs; $\alpha$ the fraction of contact pairs; $\mathrm{K}_{\mathrm{A}}$ the overall pairing constant evaluated from the association constant of contact-pairs $\left(\mathrm{K}_{S}\right)$ and the association constant of solvent-separated pairs $\left(K_{R}\right)$. The variables $f, \beta$, and $к$ have their usual meanings; $\mathrm{RX}$ (relaxation effect) and EL (electrophoresis effect) are parameters depending on the physical properties of the solvent and the temperature, given, in SI units, by: 


$$
\begin{aligned}
& \mathrm{RX}=\frac{-\beta \kappa}{6(1+1 / \sqrt{2})(1+\mathrm{t})(1+\mathrm{t} / \sqrt{2})}+\frac{\beta^{2} \kappa^{2}}{12} \ln \mathrm{t}+\beta^{2} \kappa^{2} \mathrm{FH} 2 \\
& +\beta^{3} \kappa^{3} \mathrm{FH} 3+\left[\frac{\beta_{0} \mathrm{C}^{1 / 2} \gamma^{1 / 2}}{\Lambda_{0}}\right]\left(\frac{\beta \kappa}{8}\right)[0.5 \mathrm{H} 2-\ln \mathrm{t}] \\
& \mathrm{EL}=-\beta_{0} \mathrm{C}^{1 / 2} \gamma^{1 / 2}\left[\frac{1}{1+\mathrm{t}}+\beta \kappa(0.125 \ln \mathrm{t})+0.5 \mathrm{H} 1\right] \\
& \beta_{0}=\frac{\mathrm{Fe} \kappa}{3 \pi \eta \mathrm{C}^{1 / 2}} \\
& \mathrm{t}=\kappa \mathrm{R}
\end{aligned}
$$

$\mathrm{FH} 2, \mathrm{FH} 3, \mathrm{H} 1$, and $\mathrm{H} 2$ are the interpolation polynomials introduced by Fuoss in order to facilitate solving the equation of conductance [12].

The method was used as follows: In our computer program, we used the interpolation polynomials established by Fuoss based on its model of ion pairs (1978) Eq. (1-10). In our case, we have adopted the method of calculation mentioned below. Indeed, we worked with the molar conductivity value at infinite dilution $\Lambda_{0}$ graphically obtained by extrapolation using the DebyeHuckel limiting law-Onsager. Indeed, for each electrolyte and for each concentration, we used a simple method to reproduce the experimental data of conductivity. Afterwards, we set an arbitrary value of $\alpha$ and varied the value of $R_{g}$ until a standard deviation of $\sigma$ is minimum, Eq. (11). Then, we fixed the value of $R_{g}$ and varied the value of a until a minimum standard deviation $\sigma$ was obtained to vary the radius of Gurney $\left(R_{\mathrm{g}}\right)$, by setting an arbitrary value of $(\alpha)$. Finally, we deduced the remaining Fuoss's parameters already described: molar conductivity at infinite dilution $\left(\Lambda_{0}\right)$, the fraction $(\alpha)$ and the association constant $\left(\mathrm{K}_{\mathrm{A}}\right)$. The calculated value was compared to the measured value of $\left(R_{g}\right)$ and $(\alpha)$, seeking the minimum standard deviation:

$$
\sigma^{2}=\frac{\sum\left(\Lambda_{\mathrm{J}(\mathrm{cal})}-\Lambda_{\mathrm{J}(\mathrm{obs})}\right)^{2}}{\mathrm{n}-2}
$$

$\mathrm{n}$ is the number of concentrations used during the experiment.

\section{Casteel-Amis empirical model}

To describe the relationship between the electrical conductivity with concentration, the empirical CastelAmis equation was used [13]. The empirical equation was written as follows: $\kappa=\kappa_{\max }\left(\frac{\mathrm{C}}{\mathrm{C}_{\max }}\right)^{\mathrm{a}} \exp \left[\mathrm{b}\left(\mathrm{C}-\mathrm{C}_{\max }\right)^{2}-\frac{\mathrm{a}}{\mathrm{C}_{\max }}\left(\mathrm{C}-\mathrm{C}_{\max }\right)\right]$

In this equation, $\mathrm{C}_{\max }$ is the concentration at which the specific conductivity maximum $\kappa_{\max }$ is attained. The constants (a) and (b) are arbitrarily chosen and adjusted by the least-squares method.

\section{Arrhenius equation}

On the basis of transport theory of solutions, we use the Arrhenius type temperature conductivity, which can be written as [14]:

$\kappa=A \exp \left(\frac{E_{\mathrm{a}}}{\mathrm{k}_{\mathrm{B}} \mathrm{T}}\right)$

where $\mathrm{A}=\kappa_{\infty}$ represents the maximum electrical conductivity at infinite temperature, $\mathrm{E}_{\mathrm{a}}$ is the activation energy for ionic conduction and $\mathrm{k}_{\mathrm{B}}$ is the Boltzmann constant.

\section{- RESULTS AND DISCUSSION}

The variation of the molar conductivity data for $\mathrm{LiCl}$ and $\mathrm{LiOH}$ in chitosan were analyzed by Fuoss, while the specific conductivity data were analyzed using the Casteel-Amis equation. These data are given in Table 1.

Table 1. Molar conductivities $\Lambda$ of $\mathrm{LiOH}$ and $\mathrm{LiCl}$ in chitosan at $298 \mathrm{~K}$

\begin{tabular}{lcc}
\hline $\begin{array}{c}\mathrm{C} \\
\left(\mathrm{mol} \mathrm{m}^{-3}\right)\end{array}$ & $\begin{array}{c}\Lambda \mathrm{LiOH} \\
\left(\mathrm{S} \mathrm{m}^{2} \mathrm{~mol}^{-1}\right)\end{array}$ & $\begin{array}{c}\Lambda \mathrm{LiCl} \\
\left(\mathrm{S} \mathrm{m}^{2} \mathrm{~mol}^{-1}\right)\end{array}$ \\
\hline 10 & 0.220 & 0.135 \\
20 & 0.205 & 0.120 \\
30 & 0.200 & 0.116 \\
40 & 0.192 & 0.112 \\
50 & 0.190 & 0.112 \\
60 & 0.186 & 0.110 \\
70 & 0.185 & 0.107 \\
80 & 0.184 & 0.106 \\
90 & 0.183 & 0.105 \\
100 & 0.182 & 0.104 \\
\hline
\end{tabular}

Table 2. Fuoss' parameters $\Lambda_{0}, \alpha, \mathrm{R}$ and $\mathrm{K}_{\mathrm{A}}$ for $\mathrm{LiOH}$ and $\mathrm{LiCl}$ in chitosan at $298 \mathrm{~K}$

\begin{tabular}{lcccc}
\hline & $\begin{array}{c}\Lambda_{0} \\
\left(\mathrm{~S} \mathrm{~m}^{2} \mathrm{~mol}^{-1}\right)\end{array}$ & $\alpha$ & $\begin{array}{c}\mathrm{R} \\
(\mathrm{nm})\end{array}$ & $\begin{array}{c}\mathrm{K}_{\mathrm{A}} \\
\left(\mathrm{m}^{2} \mathrm{~mol}^{-1}\right)\end{array}$ \\
\hline $\mathrm{LiOH}$ & 0.139 & 0.3 & 0.85 & $2.8 \times 10^{-3}$ \\
$\mathrm{LiCl}$ & 0.235 & 0.45 & 0.65 & $6.2 \times 10^{-3}$ \\
\hline
\end{tabular}




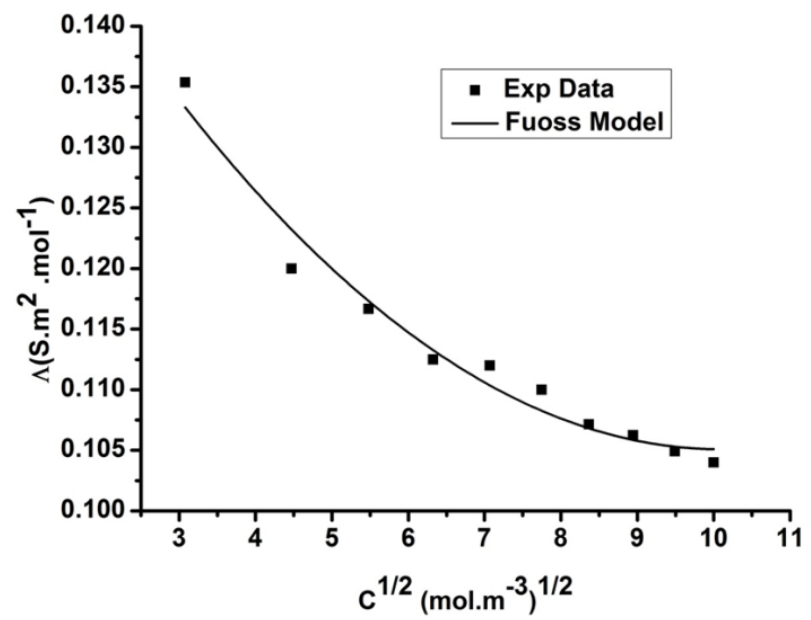

Fig 2. Molar conductivity of $\mathrm{LiCl}$ in chitosan versus $\mathrm{C}^{1 / 2}$ at $25^{\circ} \mathrm{C}$. The solid line represents the Fuoss conductance equation

The molar conductivities are plotted against the square root of the salt concentration according to the model of Fuoss in Fig. 2 and 3. As can be seen in these figures, the molar conductivity decrease when the square root of the concentration increase. The solid line was calculated using equation 1 in the model of Fuoss. Values of $\Lambda_{0}, \alpha, \mathrm{R}$ and $\mathrm{K}_{\mathrm{A}}$ obtained by this method are listed in Table 2.

The conductivity data (к) for two electrolytes were analyzed using the semi-empirical Casteel-Amis equation. They are plotted in Fig. 4. The values of the parameters $\mathrm{C}_{\max }, \mathrm{K}_{\max }$, a and $\mathrm{b}$ are given in Table 3.

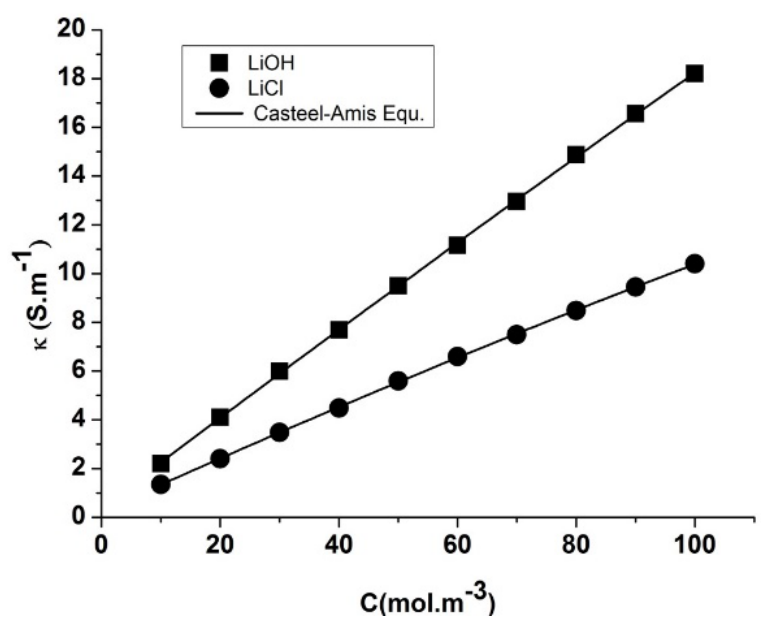

Fig 4. The specific conductance $K$ as a function of concentration $\mathrm{C}$ of $\mathrm{LiOH}$ and $\mathrm{LiCl}$ in chitosan at $298 \mathrm{~K}$

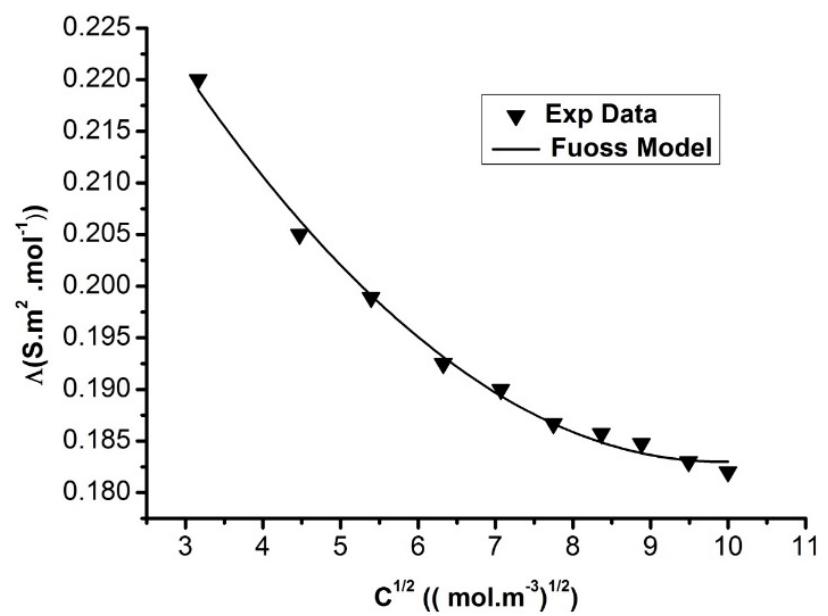

Fig 3. Molar conductivity of $\mathrm{LiOH}$ in chitosan versus $\mathrm{C}^{1 / 2}$ at $25{ }^{\circ} \mathrm{C}$. The solid line represents the Fuoss conductance equation

The value of (b) tends to be small and negative in all systems and seem to be influenced by dielectric constant. This result was previously found for $\mathrm{LiCl}$ in glycerol [15]. However, the coefficient (a) was all positive

Table 3. Casteel-Amis parameters $\mathrm{K}_{\max }, \mathrm{C}_{\max }$, a and $\mathrm{b}$ for $\mathrm{LiOH}$ and $\mathrm{LiCl}$ in chitosan

\begin{tabular}{lrcrc}
\hline & $\begin{array}{c}\mathrm{K}_{\max } \\
\left(\mathrm{S} \mathrm{m}^{-1}\right)\end{array}$ & $\begin{array}{c}\mathrm{C}_{\max } \\
\left(\mathrm{mol} \mathrm{dm}^{-3}\right)\end{array}$ & $\mathrm{a}$ & $\mathrm{b}$ \\
\hline $\mathrm{LiOH}$ & 126.9 & 1420 & 1.12 & -0.55 \\
$\mathrm{LiCl}$ & 32.9 & 590 & 1.01 & -0.45 \\
\hline
\end{tabular}

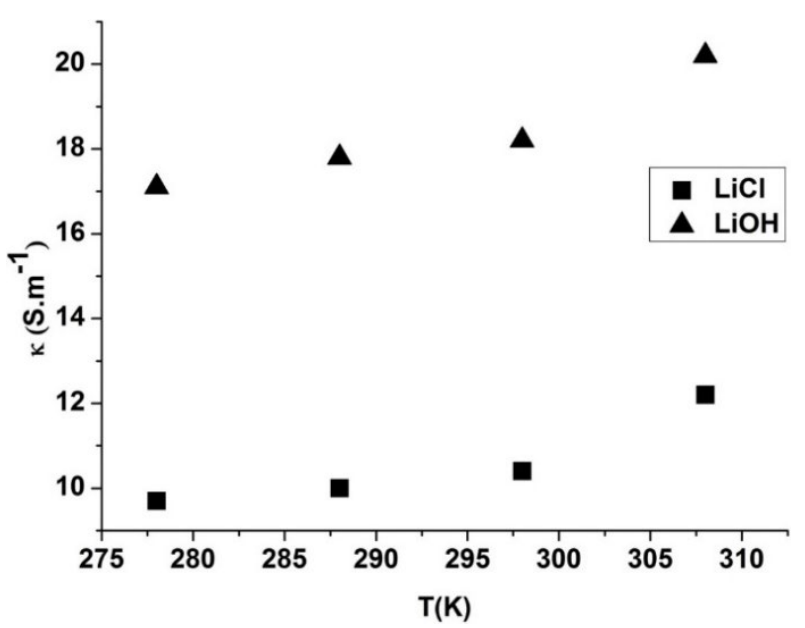

Fig 5. The specific conductance $\kappa$ as a function of temperature $\mathrm{T}$ of $\mathrm{LiOH}$ and $\mathrm{LiCl}$ in chitosan 
Table 4. The conductivities $\mathrm{K}$ of $\mathrm{LiCl}$ and $\mathrm{LIOH}$ in chitosan in the temperature range $278-308 \mathrm{~K}$

\begin{tabular}{lcccc}
\hline $\begin{array}{c}\mathrm{K} \\
\left(\mathrm{S} \mathrm{m}^{-1}\right)\end{array}$ & $\mathrm{T}=308 \mathrm{~K}$ & $\mathrm{~T}=298 \mathrm{~K}$ & $\mathrm{~T}=288 \mathrm{~K}$ & $\mathrm{~T}=278 \mathrm{~K}$ \\
\hline $\mathrm{LiOH}$ & 20.2 & 18.2 & 17.8 & 17.1 \\
$\mathrm{LiCl}$ & 12.2 & 10.4 & 10.0 & 9.7 \\
\hline
\end{tabular}

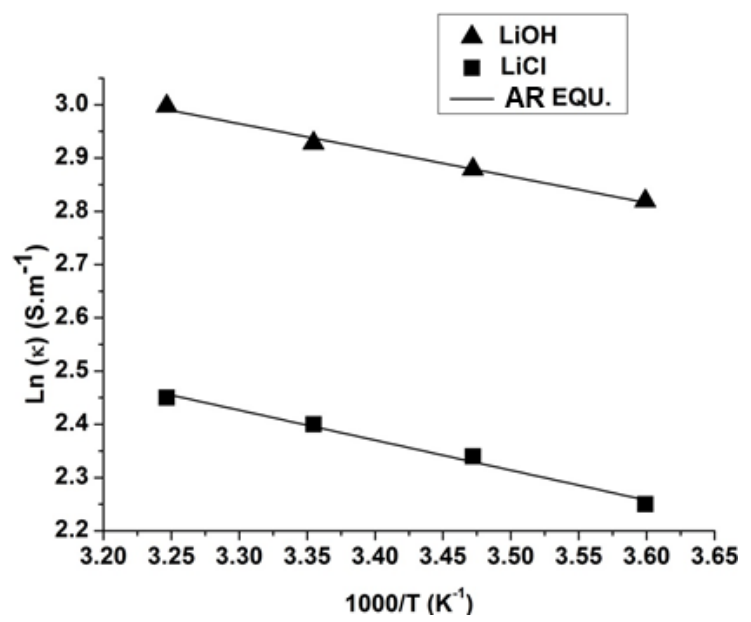

Fig 6. Arrhenius plot of the specific conductance $\kappa$ of $\mathrm{LiOH}$ and $\mathrm{LiCl}$ in chitosan

and appears to be influenced by the solution viscosity, as they have been already noticed by Christie et al. when studying conductivities of lithium salt complexes in propylene carbonate [16].

Ionic conductivity data (к) for $\mathrm{LiCl}$ and $\mathrm{LiOH}$ in chitosan, using the concentration $0.1 \mathrm{~mol} \mathrm{dm}^{-3}$ and in the temperature range $278-308 \mathrm{~K}$ are presented in Table 4 and represented in Fig. 5. We can see that the conductivity increases when the temperature increases because the viscosity of the electrolyte is reduced. In Fig. 6, we plot the natural logarithm of $\mathrm{K}$ versus $1 / \mathrm{T} \mathrm{K}$.

The maximum electrical conductivity $\left(\kappa_{\infty}\right)$ was determined by assuming a linear fit of $\ln (\kappa)$ versus $1 / \mathrm{T}$. In our case, $\mathrm{K}_{\infty}$ of $\mathrm{LiOH}$ and $\mathrm{LiCl}$ in chitosan were equal to $98.5 \mathrm{~S} \mathrm{~m}^{-1}$ and $72.24 \mathrm{~S} \mathrm{~m}^{-1}$, respectively. Then, the activation energy $\left(E_{a}=4.22 \mathrm{meV}\right.$ for $\mathrm{LiOH}$ and $\mathrm{E}_{\mathrm{a}}=4.83 \mathrm{meV}$ for $\mathrm{LiCl})$ was evaluated from the slope $\left(\mathrm{B}=\mathrm{E}_{\mathrm{a}} / \mathrm{kB}\right)$. It is noticeable that these results were also previously found by other researchers [17].

\section{- CONCLUSION}

The purpose of the present study was to test simple models for the conductivity of biodegradable electrolyte used in a clean battery. The variations of the molar conductivity with salt concentration followed Fuoss's ion paired model. The electrical conductivities of abovementioned systems have been determined to fit the empirical Gasteel-Amis equation. It was found that the values of (b) were all negative. The study presented in this paper proved that Arrhenius equation can also be used to describe the temperature dependence of the electrical conductivities. The activation energy of the electrolyte was obtained by the linear fit of $\ln (к)$ versus $1 / \mathrm{T}$. In view of these results, the electrolyte based on chitosan has been optimized and can be used in clean batteries.

\section{- REFERENCES}

[1] Zong, Z., Kimura, Y., Takahashi, M., and Yamane, H., 2000, Characterization of the chemical and solid state structure of acylated chitosan, Polymer, 41 (3), 899-906.

[2] Ji, K.S., Moon, H.S., Kim, J.W., and Park, J.W., 2003, Role of functional nano-sized inorganic fillers in poly(ethylene) oxide-based polymer electrolytes, J. Power Sources, 117 (1-2), 124-130.

[3] Mohamed, N.S., Subban, R.H.Y., and Arof, A.K., 1995, Polymer batteries fabricated from lithium complexed acetylated chitosan, J. Power Sources, 56 (2), 153-156.

[4] Yahya, M.Z.A., and Arof, A.K., 2003, Effect of oleic acid plasticizer on chitosan-lithium acetate solid polymer electrolytes, Eur. Polym. J., 39, 897-902.

[5] Yahya, M.Z.A., and Arof, A.K., 2004, Conductivity and X-ray photoelectron studies on lithium acetate doped chitosan films, Carbohydr. Polym., 55 (1), 95-100.

[6] Gray, F.M., 1991, Solid Polymer Electrolytes: Fundamentals and Technological Applications, Wiley-VCH, Weinheim, New York.

[7] Khiar, A.S.A., Puteh, R., and Arof, A.K., 2006, Conductivity studies of a chitosan-based polymer electrolyte, Physica B, 373 (1), 23-27.

[8] Fuentes, S., Retuert, P.J., and González, G., 2007, Lithium ion conductivity of molecularly 
compatibilized chitosan-poly(aminopropyltriethoxy silane)-poly(ethylene oxide) nanocomposites, Electrochim. Acta, 53 (4), 1417-1421.

[9] Singh, A.V., Nath, L.K., and Singh, A., 2010, Pharmaceutical, food and non-food applications of modified starches: A critical review, Electron. J. Environ. Agric. Food. Chem., 9 (7), 1214-1221.

[10] Rosli, N.H.A., Chan, C.H., Subban, R.H.Y., and Winie, T., 2012, Studies on the structural and electrical properties of hexanoyl chitosan/polystyrene-based polymer electrolytes, Physics Procedia, 25, 215-220.

[11] Yulianti, E., Karo, A., Susita, L., and Sudaryanto, 2012, Synthesis of electrolyte polymer based on natural polymer chitosan by ion implantation technique, Procedia Chem., 4, 202-207.

[12] Fuoss, R.M., 1978, Paired ions: Dipolar pairs as subset of diffusion pairs, Proc. Natl. Acad. Sci. U.S.A., 75 (1), 16-20.

[13] Casteel, J.F., and Amis, E.S., 1972, Specific conductance of concentrated solutions of magnesium salts in water-ethanol system, J. Chem. Eng. Data, 17 (1), 55-59.

[14] Vogel, H., 1921, Das temperaturabhängigkeitsgesetz der viskosität von flüssigkeiten, Phys. Z., 22, 645-646.

[15] Benouar, A., Kameche, M., and Bouhlala, M.A., 2015, Molar conductivities of concentrated lithium chloride-glycerol solutions at low and high temperatures: Application of a quasi-lattice model, Phys. Chem. Liq., 54 (1), 62-73.

[16] Christie, A.M., and Vincent, C.A., 1996, Conductivities of selected lithium salt complexes in propylene carbonate, J. Phys. Chem., 100 (11), 4618-4621.

[17] Bouhlala, M.A., Kameche, M., Tadji, A., and Benouar, A., 2017, Chitosan hydrogel-based electrolyte for clean and biodegradable batteries: Energetic and conductometric studies, Phys. Chem. Liq., 56 (2), 266-278. 